\title{
Strategic Network Formation with Structural Hole in R\&D Projects: The Case Study on Japanese Cosmetic Industry
}

\author{
Iori Nakaoka \\ Dept. of Business Administration, National Institute of Technology, Ube College, \\ 2-14-1 Tokiwadai, Ube City, Yamaguchi Pref., 755-8555, Japan \\ nakaoka@ube-k.ac.jp \\ Yousin Park \\ Dept. of Business Administration, Prefectural University of Hiroshima, \\ 1-1-71 Ujina-Higashi, Minami-ku, Hiroshima City, Hiroshima Pref., 734-8558, Japan \\ ecventure@pu-hiroshima.ac.jp \\ Yunju Chen \\ Faculty of Economics, Shiga University, \\ 1-1-1, Banba, Hikone City, Shiga Pref.,522-8522, Japan \\ yun-chen@biwako.shiga-u.ac.jp
}

\begin{abstract}
The arrangement of R\&D refers to the issue of the linkage between structural holes in a network. In order to examine the linkages between multiple R\&D projects in a company, we use the patent information as the index of R\&D capability and examine the change of R\&D network structures by social network analysis and text mining. In this paper we focus on top-shared companies in Japanese cosmetic industry, and suppose that these companies keep their market shares due to their smoothly development of new products to cope with the threat of new entrants from other industries. The analysis in this paper include: 1) calculate the constraint index, and create heatmaps to visualize the change of the constraint index, changes of structural holes personnel and the changes of R\&D areas the structural holes personnel involved, 2) analyze the change of the structural hole. We found that Shiseido has adopted the overconcentration organization which emphases on cooperation because the percentage of persons who belongs to the biggest sub network in patent networks of the years is high. Other companies have adopted decentralized R\&D projects which differentiated by each function. In addition, we disclosed the differences about structural hole on R\&D organization in each company.
\end{abstract}

Keywords: Strategic Network Formation, Structural Hole, Patent Applicant Network, Japanese Cosmetic Industry

\section{Introduction}

The development of new products is needed for a company to sustain its competitive advantage, while the results of development process are affected by the management of $R \& D$ projects. The arrangement of $\mathrm{R} \& \mathrm{D}$ refers to the issue of the linkage between structural holes in a network [1]. Structural hole stands in a position to control information between different areas and benefits wide range of acquisition of information.

In Japan, cosmetic industry is one of the industries that face strong competitions due to numbers of new entries. Although new entries never stop, top-shared 
companies keep their market shares in the industry. We suppose that if there is any feature in these companies' R\&D management, and the features of $R \& D$ management contribute these companies to keep their competitive advantage.

By using the patent data as the index of $R \& D$ capability, the R\&D network structures can be visualized and analyzed by social network analysis. In this paper, we focus on four top-shared companies in Japanese cosmetic industry to examine their strategic R\&D managements, especially the structural hole in the R\&D network. We experimentally visualize the R\&D networks by social network analysis based on the patent data.

The analysis include: 1) calculate the constraint index in patent applicant network, and create heat-maps to visualize the change of the constraint index, the structural hole personnel and the R\&D areas that personnel involved. The constraint index indicates the centrality of core member thus means the constraint of freedom to be the structural hole, 2) examine the change of the structural hole. The results of these analyses will be discussed to find out the reason why these companies can cope with the new entries in the perspective of R\&D management.

\section{Background}

\subsection{Structural hole and patent analysis}

The motivation for focusing on determinants of network formation comes from the large literature that has found that links in networks are associated with correlations in outcomes [2]. For example, Uzzi and Sprio find that certain network configurations are correlated with improved group performance [3].

Especially, we focus the structural hole. A structural hole is a relationship of non-redundancy between two contacts. The hole is a buffer, like an insulator in an electric circuit. As a result of the hole between them, the two contacts provide network benefits that are in some degree additive rather than overlapping. Generally, opinion and behavior are more homogeneous within same group than between groups, so people connected across groups are more familiar with alternative ways of thinking and behaving. In other words, structural hole has the benefit that brokerage across it between groups provides a vision of options otherwise unseen, which is the mechanism by which brokerage becomes social capital [4].

Patent documents are an ample source of technical and commercial knowledge. The patent is one of the indicators of capacity for technological development. There are some researches aim at visualizing and analyzing patents, or proposing efficient text-mining approaches for creating patent maps. However, there are few researches focusing on management strategies based on text-mining analysis of patents.

\subsection{The overview of cosmetic industry}

Although the expansion of market scale benefits the Japanese cosmetic companies to keep their growth, the mature of cosmetic market and customer slow down cosmetic companies' speed of growth. The total sales of the industry have kept flat since the beginning of 2000 , however, new comers from other industry entered one after another after 2000. There are 12 large new comers into cosmetic industry and their entries concentrated on 2006-2009. But the top 5 shared companies occupied the $80 \%$ of the total sales of the cosmetic market. For example, the shares of sales of top 5 companies in 2014 were: Shiseido 37.9\%, Kao 28.4\%, Pola Holdings 9.5\%, Kose 9.5\%, Mandom 3.4\%. Figure 1 shows the sales of Shiseido and Pola from 2008-2014. We found that sales of each company kept growing even after 2009, which the new entries most intensively appeared.

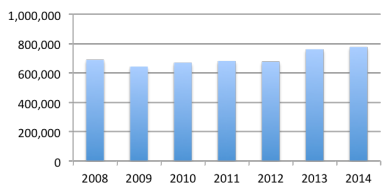

(a) Shiseido

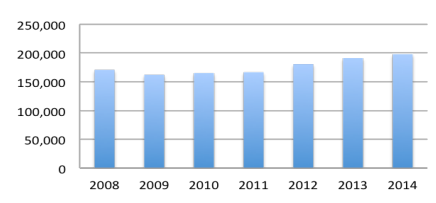

(b) Pola
Figure 1 The sales of each company

In order to answer the question that how Japanese cosmetic companies manage their R\&D networks, we compare and identify their differences and patterns of R\&D strategies by visualization of patent analysis though text-mining and social network analysis. Target companies for analysis are Shiseido, Kao, Pola and Kose. 


\section{Methodology and data}

In the following sections, the trends of $R \& D$ project management strategies of Japanese cosmetic companies are analyzed. In order to examine target companies' R\&D strategies and the change of R\&D network, we visualize their patent data in 4 steps: 1) the number of patent publications in each company, 2) the constraint index of R\&D network (patent applicant network) as structural hole by social network analysis, 3) the human resource reallocation of personnel engaged in $R \& D$ project, 4) changes of $R \& D$ areas that structural hole personnel involved. Diagrams are created by these analyses.

We define that patent applicants are key persons attaining low scores calculated by constraint of social network analysis. As mention above, the constraint index indicates the constraint of freedom to be the structural hole. Since personnel who connect organizations play the role as the structural hole serves to relay the information, we use constraint index to visualize the changes of structural holes connection personnel in this paper.

In addition, patent applicants' change does play a central role in the $R \& D$ as a major variable of the strategic network formation. Where core member with low constraint index can be seen as the structural hole, we examine the change of constraint index and define the change as conditional probability. The index is summed up whether or not lower rank $j \%$ of person at $i$ year appears lower rank $j \%$ of person at $i+1$ year (lower rank $j \%$ of person at $i+1$ year)/ (lower rank $j \%$ of person at $i$ year). If the probability is high, it means that the rate of structural hole personnel remained in the next year is high. Changes of R\&D area are also analyzed to see the relationship with the changes of structural holes. Heat-maps are created to visualize the results.

In Japan, patent documents are archived in J-PlatPat, and are browsed and retrieved ubiquitously. All patents are classified according to each three classification codes, IPC (International Patent Classification), FI (File Index) and F-term (File Forming Term). Both of FI and F-term are classification codes under IPC. Especially, F-term is given to every patent from F-term list based on the technical items indicated in patent documents. Thus, almost every patent has multi-F-term codes. Table 1 is most frequently used F-terms in cosmetic
Strategic Network Formation with

industry. Based on these F-term related to cosmetic, patents related to cosmetic published by each company are extracted and collected from the patent data.

\section{Analysis}

\subsection{An approach based on the number of patent publications}

As our first approach, the numbers of patent publications associated with cosmetics in each of the companies are shown in Figure 2.

Every company obtains related patents to a certain extent and the number of patents held by all the companies kept on decreasing during the years. Shiseido and Kao obtain more than 200 patents every year but the rates of R\&D spending and net sales fell. However, we can consider that R\&D of Shiseido is efficient because the rate of $R \& D$ spending and net sales of Shiseido is lower than Kao.

Table 1 F-term list of cosmetic patents

\begin{tabular}{lll}
\hline F-term & \multicolumn{2}{c}{ Contents } \\
\hline 4C083AA & NATURAL INGREDIENTS AND INGREDIENTS \\
& WITH UNKNOWN STRUCTURES AND \\
& $\begin{array}{l}\text { COMPOSITIONS } \\
\text { INORGANIC INGREDIENTS }\end{array}$ \\
4C083AB & $\begin{array}{l}\text { ORGANIC INGREDIENTS CHARACTERIZED } \\
\text { 4C083AD }\end{array}$ & $\begin{array}{l}\text { BY ELEMENTS } \\
\text { ORGANIC INGREDIENTS CHARACTERIZED }\end{array}$ \\
4C083BB & FUNCTION SPECIFIC INGREDIENTS \\
4C083CC & KINDS OF PRODUCTS \\
4C083DD & FORMS OF PRODUCTS \\
4C083EE & EFFECTS \\
4C083FF & METHODS, DEVICES FOR MANUFACTURE \\
\hline
\end{tabular}

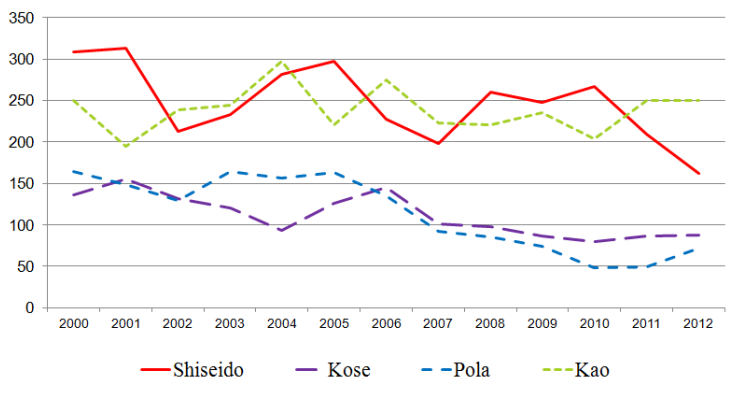

Figure 2 The number of patents of each company 


\section{$4.2 R \& D$ network (patent applicant network)}

We disclose the R\&D organizational structures of the target companies by the social network analysis in this section. Figure 3 shows the R\&D networks of each company in 2010. These figures are constructed by nodes that personnel engaged in R\&D and edges of joint patent applicants.

We can consider that Shiseido has adopted the overconcentration organization which emphases on cooperation because the percentage of persons who belongs to the biggest network in all of the years is high. On the other hand, other companies such as Pola and so on have adopted decentralized organizations which differentiated by each function. And also, the trend can be seen in almost all of the year.

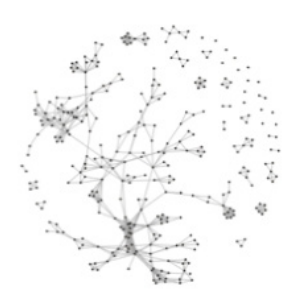

(a) Shiseido

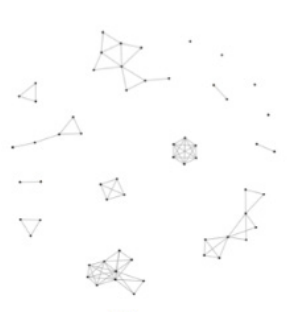

(c) Pola

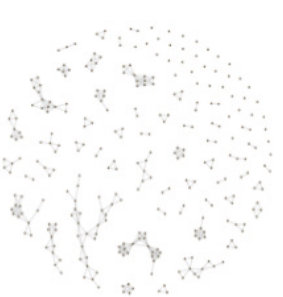

(b) Kao

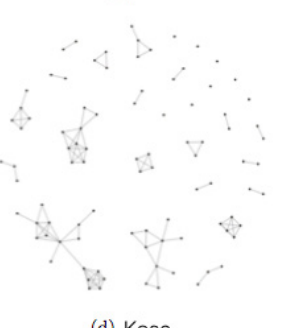

(d) Kose
Figure 3 R\&D networks of each company in 2010

\subsection{The strategic network formation}

We focus on the change of $R \& D$ areas that structural holes connection core personnel involved in to express how the structural holes personnel develop new technologies.

We visualize the human resource reallocation of personnel engaged in $R \& D$ project by heat-map. Where the color is dark in heat-map, it indicates an unexecuted reallocation of a core engineer; otherwise, the color is light, it means a radical change of core member in that year.
The changes of structural holes personnel and the changes of R\&D areas the structural holes personnel involved in each company are shown in Figure 4 and 5. There is no significant change both in Shiseido's structural holes personnel and R\&D research areas that structural holes personnel treat. Since $30 \%$ of structural holes personnel left to the next year in every year in Shiseido, we can consider that Shiseido has been taken in a planned and consistent way in the $R \& D$ management.

On the other hand, other companies have worked on a new technology in the periodic switching of the human resources, because both light and dark colors are combined in the figures and changes of shade in other companies are greater than Shiseido in each year. Compare to Shiseido, other companies respond to market changes.

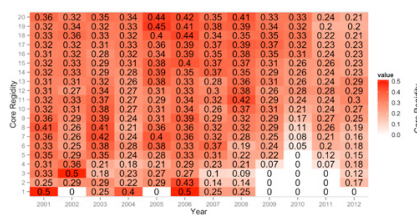

(a) Shiseido

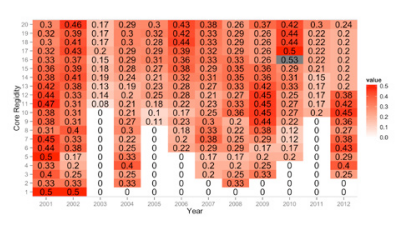

(c) Kose

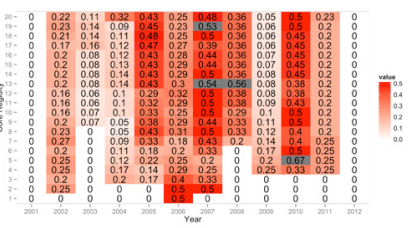

(b) Pola

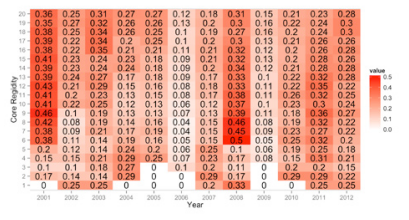

(d) Kao

Figure 4 The changes of structural hole personnel of each company

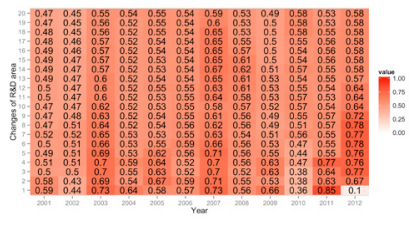

(a) Shiseido

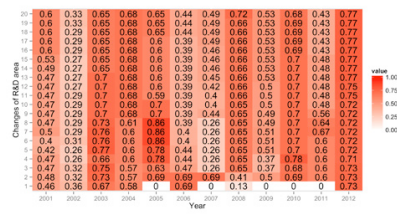

(c) Kose

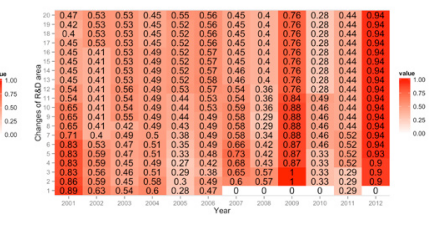

(b) Pola

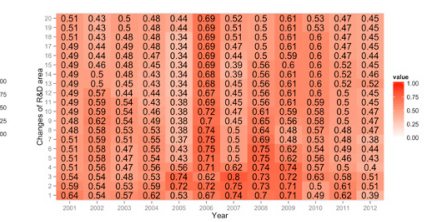

(d) Kao

Figure 5 The change of $R \& D$ areas that core structural hole personnel involved in 


\section{Conclusions}

In this paper, we visualized $R \& D$ organization network of Japanese cosmetic companies using the social network analysis. We revealed the differences between Shiseido and other companies. We found that Shiseido has adopted the overconcentration organization which emphases on cooperation because the percentage of the person who belongs to the biggest sub network in patent networks of the years is high. Other companies have adopted decentralized R\&D project which differentiated by each function. In addition, we disclosed the differences about structural hole on R\&D organization in each company. From the results, we can consider that Shiseido as the leader of the industry has been taken in a planned and consistent way and other companies respond to market changes.
Strategic Network Formation with

As further works, the patent data of the other country and the other companies should be carefully examined. We would like to modify our approach into more sophisticated one and to build up a more reliable theoretical background.

\section{References}

1. Burt, R. S. (2004). Structural Holes and Good Ideas American Journal of Sociology, Vol. 110, pp. 349-399

2. Christakis, N., Fowler, J., Imbens, G., and Kalyanaraman (2010), "An Empirical Strategic Network Formation" NBER Working Paper

3. Uzzi, B. and J. Spiro, (2005), "Collaboration and Creativity: The Small World Problem," American Journal of Sociology, Vol. 111, pp. 447-504.

4. Burt, R. S. (1992). Structural holes: The social structure of competition". Cambridge, MA: Harvard University Press. 